\title{
Study on the Problems in the Urban Village Reconstruction
}

\author{
DangChen Sui \\ School of International Business \\ Shaanxi Normal University \\ Xian, China \\ suihu7672@snnu.edu.cn
}

\author{
Xing Yu Yao* \\ School of International Business \\ Shaanxi Normal University \\ Xian, China \\ 742911031@qq.com
}

\begin{abstract}
With the rapid development of cities in China, the social phenomenon of urban villages has emerged at the same time. Although urban villages contain a large number of migrant populations and relieve the pressure of housing in cities, problems of public security and environment force the reconstruction of urban villages to be necessary. This paper thinks that the transformation of urban villages will produce the problems such as simple transformation methods, difficult coordination of interests and neglect of the interests of migrant populations, and it puts forward suggestions including a targeted planning plan, formulation of reasonable compensation programs, coordination of multiple benefits and consideration of housing problems and pressure of migrant populations.
\end{abstract}

Keywords-Urban villages; Transformation; Migrant populations

\section{INTRODUCTION}

Since the 21 st century, the urban development of our country started late, but the development momentum is swift and violent. China's GDP rose from \$2 trillion in 1982 to more than 80 trillion dollars in 2017. In just 35 years, GDP has increased by nearly 40 times. In such a rapid urban development, some negative externalities, such as environmental pollution, will inevitably occur. However, there are some problems in urban development itself, in which the phenomenon of village in city is inevitable in the process of urban development.

The number of in-city villages in first-tier cities is obviously higher than that in second-third-tier cities. The phenomenon of village in city reflects the conflict between modernity and traditional ideas and the expansion of contradiction in the process of urbanization [1]. In the development and expansion of modern cities, when the traditional rural areas around the city are involved, the requisition price of agricultural land is lower than that of the rural collective construction land (mainly refers to the homestead). Therefore, all or most of the agricultural land is expropriated. The countryside loses farmland, is surrounded by a rapidly growing city, and forms a village in the city on the landscape; a farmer. People lose their farmland and have no source of income, so most landless farmers have to rely on rental houses to earn their income, which formally forms a village in the city.

\section{NECESSITY OF REBUILDING URBAN VILLAGE}

The management of villages in cities is free from the urban management, which is the embodiment of the dual structure of urban and rural areas in China [2]. There are many problems due to the location factors and institutional factors of villages in the city. We can divide the problem of the village in the city into two categories: the first is the problem of the village in the city for the whole city, and the second is the problem inside the village in the city. In the first category, the main problems are as follows: first, the existence of the village in the city affects the landscape of the whole city. The culture and architecture of the city are modern, while the rural areas are representative of tradition. Both of them exist in the same area, which is bound to be manifested in the architecture of the two. Landscape and other incompatible, affect the overall landscape of the city. Second, the village in the city will lead to the dislocation of the urban functional areas in the area. The location of the village in the city is often close to the bustling part of the city. This has higher requirements for the area in which the village is located. Obviously, the village in the city cannot accomplish the mission of the higher function zone. Thus affecting the planning and development of urban areas. Thirdly, villages in cities have negative externalities. Although the village in the city is located in the city, it is outside the management of the city, while the resident population of the village in the city is mainly an alien population (the population mainly refers to the rural area, the level of education is relatively high. The low number of migrant workers may have a negative impact on the security and environmental hygiene around the villages in the city. In the second kind of problems, the problems mainly focus on the inside of the village. The first, the living environment of the village in the city is dirty, disorderly and poor. Because of their geographical advantages and relatively low prices, the rental houses of the villages in the city are the first choice for the foreign population. In the face of the housing needs of such a large number of foreign people, local residents will prefer to rebuild their houses. In order to provide more rental housing to earn income, while roads, public green space and so on are also the largest encroachment, resulting in the village in the city The road congestion, the public green space almost disappear, everywhere visible "face building" "kiss building" phenomenon and so on, these problems not only affect the quality of life of migrant workers, but also bring fire safety risks. Second is a serious shortage of public security in the 
village in the city, easy to become a place of social crime and dirt. Because of the village in the city village. The housing lacks the corresponding management mechanism and safety protection measures, which makes the village theft more serious, and easily become a gathering place for criminals and illegal organizations such as pyramid marketing. The third category is the poor environmental sanitation in the villages in the city. Sewage, flies, mosquitoes, smell is more common, which may become a high incidence of infectious diseases. Due to the limited space of the article, the problems existing in the village in the city will not be described one by one, but from these problems we can see that the transformation of the village in the city is very necessary.

\section{PROBLEMS EXISTING IN THE RECONSTRUCTION OF URBAN VILLAGE}

The transformation of villages in cities has been carried out in cities throughout the country in earlier years, but there are still some problems in the transformation, which are mainly manifested in the following three aspects:

First, the method of transformation is simple.

The transformation of the village in the city is the process of replanning, integrating and utilizing the land resources of the city. However, less consideration is given to the actual situation and needs of the region. Although the villages in the city are located in the city, they also have their inherent traditional culture, characteristics, large-scale demolition and unified planning, which will result in the destruction of the traditional culture of the villages in the city and the loss of their own cultural characteristics. In the end, it is the same building made up of steel and cement. Mumford, a thinker on urban planning in the United States, once criticized this kind of planning: "the street must be written." Straight, not turned, nor can the width of the street be reduced by a few feet to protect a precious old building or a rare old tree. "[3]

Second, it is difficult for the parties concerned to coordinate with each other.

For the transformation process of village in city, it is the process of value-added and redistribution of benefits. The benefit of increment comes from land, and the increment of land includes artificial multiplication and natural increment, in which artificial multiplication refers to the increase of land directly brought by developers' investment in land, human capital and so on in the process of transformation. Natural value-added refers to the increase of land value caused by the increase and improvement of infrastructure and industrial agglomeration after transformation, both of which are reflected in the rise of land price [4]. Since in the process of consolidation, the actual stakeholders are only the government, developers and local residents or village collectives, The main body of interest is out of the economic person's egoism, and they all want to get the greatest benefit from the land increment as much as possible. It can be said that the root cause of many problems in the reconstruction of villages in the city is that the benefit parties are seizing limited resources [5]. This will bring a lot of trouble to the whole transformation work, the production of nail households is mostly based on this, hinder, delay the entire process of transformation, but also not conducive to social harmony.

Third, it is easy to ignore the related interests of the foreign population.

The village in the city contains a large number of foreign population, but in the whole process of transformation, the most easily neglected is the migrant workers who are always in the weak side. Because they belong only to the tenants of the village houses in the city, but the renovation works will undoubtedly have the greatest impact on them and are unfair. Because the rapid development of cities in our country has not only benefited from the progress of science and technology, but also by the transfer of rural population dividends to cities. Zhu Baoshu also discussed that the development of cities in the 21 st century has benefited from the demographic dividend. The vitality of many large immigrant cities, such as Shanghai, is the demographic dividend from the countryside [6]. It can be seen that the foreign population has contributed to the development of the city, but because of the transformation of the villages in the city, they have to choose another place to live, most of which are far away from their places of work, or where the rent is expensive. Affected the life of migrant workers. As to the destination of the foreign population after the transformation of the village in the city, some scholars investigate and analyze it. Finally, it is concluded that there are two main directions for the foreign population in the face of the transformation of the village in the city: to move to other villages in the city and to return to their hometown [7]. Not only will they increase their cost of living, but also, to some extent, they will affect the development of the city due to the lack of corresponding labor force. Integral Pareto improvements to the welfare of each city will also be reduced by this, and if their housing problems are not properly considered, it will only cost a lot of money to exacerbate the problem of one "slum"[8] into another. As a result, they will not only increase the corresponding cost of living, but also affect the development of the city to some extent due to the lack of corresponding labor force, and the Pareto improvement of the whole city's welfare will also be reduced because of this.

\section{RELEVANT POLICY RECOMMENDATIONS}

\section{First, the targeted planning scheme}

The large-scale demolition and construction of villages in cities not only causes the loss of resources, but also brings assimilation of the traditional characteristics of villages in cities. The government should do the following three things to minimize the problems caused by demolition and construction. First, the transformation of the village in the city is not an immediate project, but a long-term project, which requires us to consider the combination of long-term and short-term interests. For the reconstruction of the village buildings in the city is important, more important to the transformation of people. Therefore, at the same time, we should also pay attention to the vocational skills of local residents or financial skills training, otherwise it is likely to cause the transformation of the village landscape and the city. Fusion, but functional may be a flash in the air, pavilions. Second, in the process of village planning after transformation, the government should fully consider the opinions of all 
stakeholders, especially the village collectives and residents, and protect the representative traditional cultural buildings or other facilities in the villages. At the same time, for the reconstructed landscape architecture, a reasonable planning scheme is designed to make the reconstructed village in the city have its own original characteristics, and it can perfectly conform to the development situation of the whole city, instead of all the transformation of the one-size-fits-all. Strive to achieve the "one Village one case". Finally, the construction of the village in the city should be demolished selectively, and some of the buildings should be built. The completion of the building is relatively recent, if it is dismantled, it will cause a waste of social resources.

Second, Make reasonable compensation plan and coordinate the benefit of all parties

The problem of the coordination of interests is the biggest problem in the process of rebuilding the villages in the city. How to coordinate is suggested from the following three aspects: first, the government should determine a scientific and reasonable compensation scheme for demolition and relocation. Compensation for local residents in the plan should be specific analysis, can not generalize. Second, more publicity should be given to the demolition plan in the villages in the city, so that local residents can have a clear understanding of the policy and planning of the demolition. This will to a certain extent avoid hindering the removal of the government by residents because they do not have a good understanding of policies and plans, and increase the participation of farmers in the process of transformation. . At the same time, in order to reduce the cost of the government, and in view of the problem of the nail households, the government can appropriately adopt the method of letting the village collective to solve the problem-residents who support the demolition will put pressure on the nail households because they want to get the income from the demolition as soon as possible. These pressures come from the traditional relationships of relatives and neighbors in rural areas. This solution can reduce the social cost and avoid affecting social harmony. Third, for developers, the government should first do a good job in the selection of developers, select good developers with good quality and reputation, to ensure reasonable profits of developers, can provide appropriate preferential policies, for the planning plan the government has to levy After the comprehensive urban master plan, determine the reasonable commercial and residential ratio, housing volume ratio and so on, at the same time through the relevant departments and the public to supervise, to ensure that developers strictly in accordance with the government plan to implement.

Third, considering the housing problem and pressure of the foreign population

For the foreign population which is easy to be neglected, the most important consideration is the cost of living of the foreign population after the transformation, which is related to whether the transformation belongs to the Pareto improvement of the social welfare of the whole city. The government can do as much as possible to protect the housing problem of the rural migrant population in the transformed city. First, if there is sufficient land area in the villages in the city, the government can negotiate with the village collectives and residents and expropriate part of the land for the construction of the infrastructure necessary for the city, and the remaining land will be handed over to the village collectives and the residents for independent development. To use and solve the housing problems of the foreign population and to some extent ease the city the pressure on the market for rental housing [9]. Second, according to the actual local conditions, according to the service radius, the government can reasonably design special land in the planning for the construction of the residence of the foreign population, and at the same time solve the housing problem of the foreign population. It also provides the government with human resources for urban development. Third, of course, some regions (such as Suzhou) have adopted the progressive upgrading of industries to reduce laborintensive industries and improve the labor skills of foreign workers so as to raise their income levels. To enable them to rent higher-rent housing and raise the standard of living of the foreign population, in such a way as to Industry to control the foreign population, but also to some extent reduce the pressure of urban life [10].

\section{CONCLUSION}

The phenomenon of village in city is not only a problem in the development of city, but also a problem of social formation, which is very necessary for the transformation of village in city. However, the problem of villages in the city cannot be dealt with in a general way. It is necessary to clear out the position of social groups in the transformation process, identify the root causes of the problems, and design a targeted planning plan to ensure that the losses suffered by all parties in the transformation are minimal. To maximize the welfare of the whole city. 


\section{REFERENCES}

[1] Hang Ma, Renewal of City Village in ShenZhen from Perspective of Urban sociology[J].city planning,2007(1):26-32.(In Chinese)

[2] FengKai Su, HuaJie Wang. Identification and treatment of the Nature of Building in the process of rebuilding Village in City [J]. Urban construction supervision, 2007(3):19-20. (In Chinese)

[3] Mumford Lewis. The City in History, Its Origins, Its Transformation, and Its Prospects [M]. Harcourt, Brace \& World, Inc, 1961.

[4] XiaoPing Shi, ZiBo Wei, Jie Sun, How to distribute the land value-adde d income more reasonably. http//opinion.caixin.com/2016-07-11/100965 110.html.(In Chinese)

[5] Shenghua Jia, WenJuan Zheng, ChuanHao Tian, The Theory and Countermeasures of stakeholder Governance in the Reconstruction of Village in City[J].city planning,2011,35(05):62-68.(In Chinese)

[6] ShuBao Zhu, The differential characteristics of Urban Alien population and the relevant Policy Inspiration--Take Shanghai as an example [J]. Journal of East China normal University (philosophy and Social Sciences Edition),2008,40(1):48-53.(In Chinese)

[7] Huaqian Chang, Chaolong Chen, An Analysis of the characteristics of the Alien population in the process of the Transformation of the Village in the City-A case study of Tianhe District, Guangzhou City [J]. Journal of South China normal University (Natural Science Edition),2012,44(4):128-132.(In Chinese)

[8] Jacobs Jane. The Death and Life of Great American Cities [M].England: Penguin Books Ltd, 1961.

[9] Ran Tao, RuiMin Wang, Transformation of villages in cities and Land system Reform in China: breakthrough and limitation in the Pearl River Delta [J]. International Economic Review.2014(03):26-55.(In Chinese)

[10] JiHong Ye, Governance of villages in cities: problems, dilemmas and Lilue-A case study of Chengwan Village [J]. Administrative forum2016,23(3):69-74.(In Chinese) 